\title{
Metodologias de Pesquisas Pós-Críticas: possibilidades para a saúde e a enfermagem
}

Maria Henriqueta Luce Kruse Franciele Roberta Cordeiro ${ }^{2}$ Stefanie Griebeler Oliveira ${ }^{3}$ Camila Castro Roso ${ }^{4}$

$\mathrm{P}$ esquisar. Inventar. Interrogar. Problematizar. Suspeitar. Compor, decompor e recompor. Descrever e analisar. Com esses verbos, iniciamos a reflexão acerca do livro Metodologias de Pesquisas Pós-Críticas em Educação(1). Tais verbos abrangem os modos de fazer e pensar a pesquisa nos referenciais que "fogem", de algum modo, dos princípios investigativos propostos pela ciência tradicional e positivista, como a racionalidade, a universalidade, a objetividade, e a neutralidade. Os diferentes capítulos problematizam metodologias pós-críticas, apresentando-as como ferramentas que compõem estratégias metodológicas que auxiliaram pesquisadores do Grupo de Estudos e Pesquisas sobre Currículos e Culturas (GECC), da Universidade Federal de Minas Gerais, e do Grupo de Pesquisa em Educação e Relações de Gênero (GEERGE), da Universidade Federal do Rio Grande do Sul, a pensar suas pesquisas no campo educacional e da saúde. O referencial pós-crítico que o livro apresenta tenta "desconstruir" discursos e métodos de produção de conhecimento, desnaturalizando-os, explorando métodos alternativos, construindo metodologias na investigação. Os autores dos capítulos do livro destacam os referenciais pós-críticos com o predomínio do paradigma da invenção, que permite o afastamento e concebe as verdades como construções interessadas, que disputam em um campo de lutas. O texto desponta com efeito multiplicador quando direcionamos suas linhas, seus traços, para a área da saúde e da Enfermagem. $O$ livro engloba diferentes lentes e modos de pesquisar, na perspectiva dos Estudos Culturais, a partir de referenciais teóricos estruturalistas e pós-estruturalistas, estudos feministas, coloniais e pós-coloniais, ligados à filosofia da diferença. Operar com as ferramentas disponibilizadas por tais perspectivas possibilita lançar olhares diferenciados para temáticas tidas como "comuns" e naturalizadas. A leitura do livro possibilita colocar em xeque verdades metodológicas rígidas, pois auxilia a encontrar caminhos para responder a nossas inquietações, instigando a questionar, a estranhar e a desconfiar das maneiras como "produzimos" nossas informações. Dentre as singularidades possíveis de serem apreendidas por meio dessas metodologias encontram-se novos modos de fazer, olhar e inventar sujeitos, com diferentes modos de pensar, agir e governar condutas e corpos. Os artigos que compõem o livro apresentam as possibilidades de pesquisa com diferentes artefatos, sejam eles midiáticos, científicos, religiosos, artísticos. Os mesmos referem-se a pesquisas com abordagens qualitativas, do tipo etnografias, netnografias e cartografias que se utilizam de narrativas, entrevistas (presenciais ou virtuais), grupos focais, análises enunciativas de músicas, documentos, imagens, filmes e outras formas de "produzir dados". Em cada experiência, são pontuados aspectos fortes e frágeis do uso do método. Um exemplo disso é o uso da entrevista on-line, que reduz o tempo de transcrição, possibilitando o acesso a diferentes informantes em diversos lugares, enquanto preserva o anonimato. Outro exemplo é a etnografia pós-moderna que dá voz ao sujeito pesquisado, constituindo uma crítica à etnografia clássica, onde a presença do pesquisador parece ser excessiva, já que a descrição etnográfica se dá a partir de quem descreve e não de quem é descrito. Não há uma "receita" para utilização desses métodos. Eles devem ser (re)inventados conforme cada objeto de pesquisa, cada contexto. Nas análises dos dados produzidos, busca-se descrever e problematizar os enunciados que são tomados como monumentos. Em vez de buscar uma origem ou uma verdade escondida, vislumbrase a centralidade da linguagem na significação do mundo e a inseparabilidade entre linguagem, cultura, verdade e poder. Assim, a partir da análise desses enunciados, é possível descrever posições de sujeito que o indivíduo pode ocupar. Por fim, compartilhamos com as autoras que dentro da perspectiva pós-crítica não existe receita a ser seguida ou jeito certo de pesquisar. Talvez a grande novidade seja possibilitar a invenção a partir das demandas que surgem no decorrer do tempo e das experiências do pesquisador, sem o estabelecimento de um a priori. Mais interessante do que ditar certos modos de fazer e refazer pesquisa na enfermagem e na saúde é permitir a ascensão da diferença, do novo, da invenção. E porque não, a partir de um lançar de dados, ou simplesmente ao acaso? Melhor qualidade de vida aos seus praticantes.

\section{Referência}

1. Meyer DE, Paraíso MA. Metodologias de pesquisas pós-críticas em

educação. Belo Horizonte: Mazza Edições; 2012.

1 Enfermeira. Doutora em Educação. Professor Associado da Graduação e da Pós-Graduação em Enfermagem da Universidade Federal do Rio Grande do Sul, UFRGS. E-mail: kruse@uol.com.br

2 Enfermeira. Mestranda do Programa de Pós-Graduação em Enfermagem da Universidade Federal do Rio Grande do Sul. Bolsista CAPES.

3 Enfermeira. Doutoranda do Programa de Pós-Graduação em Enfermagem da Universidade Federal do Rio Grande do Sul (UFRGS). Professor Assistente da Universidade Federal de Pelotas (UFPEL).

4 Enfermeira. Doutoranda do Programa de Pós-Graduação em Enfermagem da Universidade Federal do Rio Grande do Sul (UFRGS). Bolsista CAPES. 
눌

\section{Responda a}

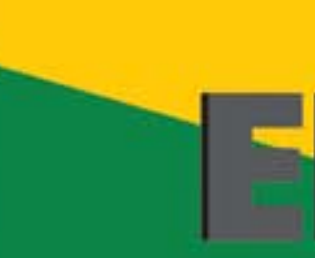

$$
\begin{gathered}
\text { Pesquisa } \\
\text { pela Internet }
\end{gathered}
$$
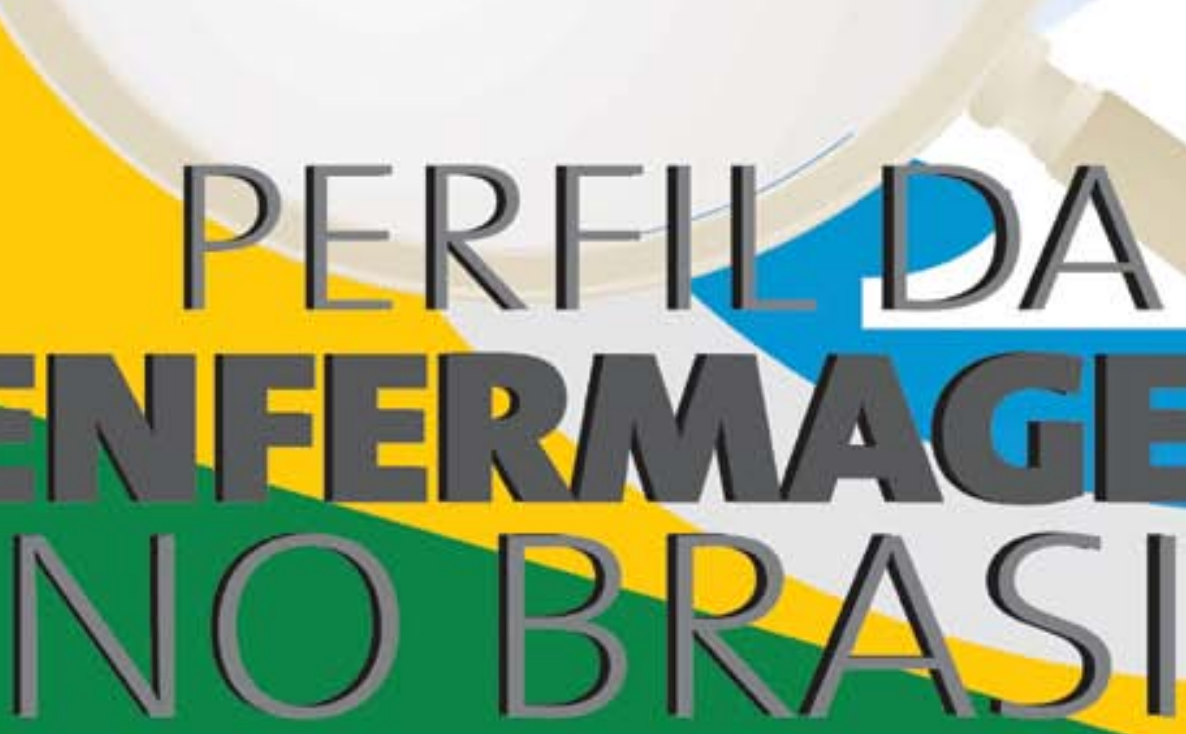

Sua participação é muito importante para o futuro da categoria

ACESSE E RESPONDA A PESQUISA EM WWW.ESNP.FIOCRUZ.BR/PERFILDAENFERMAGEM

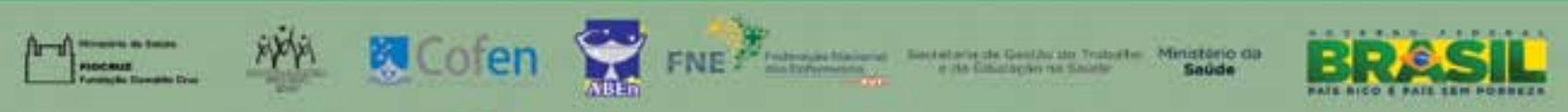

